\title{
EDITORIAL
}

\section{PJ ZEON Award for outstanding papers in Polymer Journal 2013}

Polymer Journal (2014) 46, 313-314; doi:10.1038/pj.2014.18

$\mathrm{T}$ he winners of the 2013 PJ ZEON Award have been announced by the Society of Polymer Science Japan (SPSJ). The award is open to all first authors of papers published in Polymer Journal, who are under the age of 38 years at the time of submitting their paper. For 2013, the winners are as follows:

Dr Chie Kojima (Osaka Prefecture University, Japan) for the contribution 'Synthesis and binding properties of peptidomimetics based on a dendritic polymer', Vol. 45, No. 3, 2013.

Dr Keiji Numata (RIKEN Biomass Engineering Program, Japan) for the contribution 'Synthesis of poly-and oligo(hydroxyalkanoate)s by deep-sea bacteria, Colwellia spp., Moritella spp., and Shewanella spp', Vol. 45, No. 10, 2013.

Academic profiles of the winners can be found below this announcement.

Dr Kojima and Dr Numata received their award certificates and medals at an award ceremony held in conjunction with the SPSJ annual meeting in May 2014 in Nagoya. Each winner also received a cash prize of 300000 yen and presented an invited talk based on their respective papers.

On behalf of the editors and editorial board of Polymer Journal, I wish to congratulate Dr Kojima and Dr Numata on this welldeserved honor in recognition of their excellent papers. ${ }^{1,2}$ I hope the award will provide encouragement to these young researchers and will be one of many awards they will receive throughout their bright careers.

I hope this award will encourage submissions from eligible authors to Polymer Journal. I am looking forward to receiving many applications for the 2014 PJ ZEON Award. Each year the SPSJ selects up to three most outstanding papers published by young authors in Polymer Journal, as recommended by the selection committee and board of directors of the SPSJ. Although we have selected two papers for 2013, we selected three for $2012 .^{3}$ Those who are interested should go to the SPSJ website (http:// main.spsj.or.jp/) for further information. Finally, let me extend our sincere appreciation to Zeon Corporation for their generous sponsorship of this award.

Takashi Kato Editor-in-Chief

\section{ABOUT THE WINNERS}

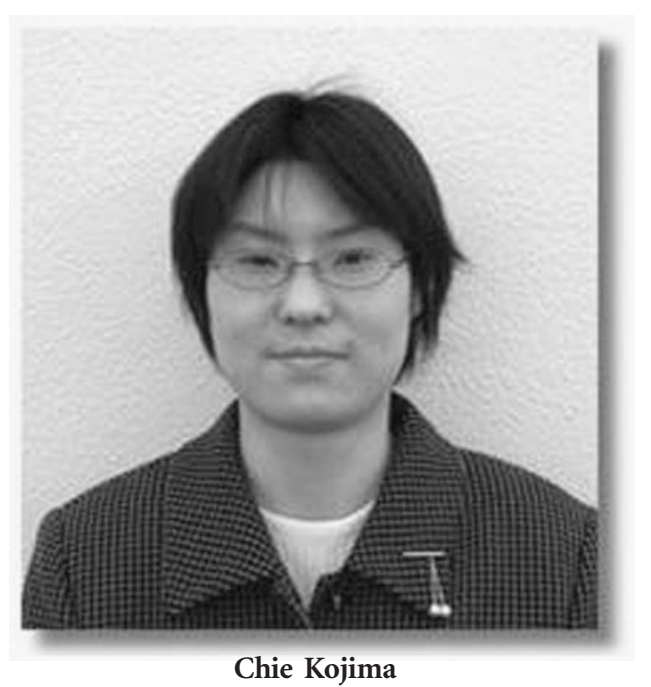

Dr Kojima received her $\mathrm{PhD}$ degree in Biostudies from Kyoto University in 2005 under the supervision of Professor Hisataka Sabe. She worked at Osaka Prefecture University (OPU) as an assistant professor with Professor Kenji Kono from 2005 to 2008. She became a visiting scientist in National Cancer Institute/National Institutes of Health (USA) in 2008. Then, she established her own laboratory in OPU as a tenure-track lecturer in 2009. She was then promoted to an associate professor. Her current research interests include biomedical application of dendrimers.

About the award article: Dendrimers have well-defined structures and multiple terminal functional groups at the periphery. The authors designed a novel type of peptidomimetics based on a dendrimer. Various acetylated amino acids were conjugated to the dendrimer periphery at different ratios, and fluorescent dye was conjugated to the dendrimer core for detection. A proline- and arginine-bound dendrimer was synthesized as a proline-rich peptidomimetic, and the binding to src homology 3 (SH3) domain was investigated as a model. The peptidomimetic was associated with the $\mathrm{SH} 3$ domain at a similar level to a linear proline-rich peptide, suggesting that the amino acid-bound dendrimers are a potent peptidomimetic. 


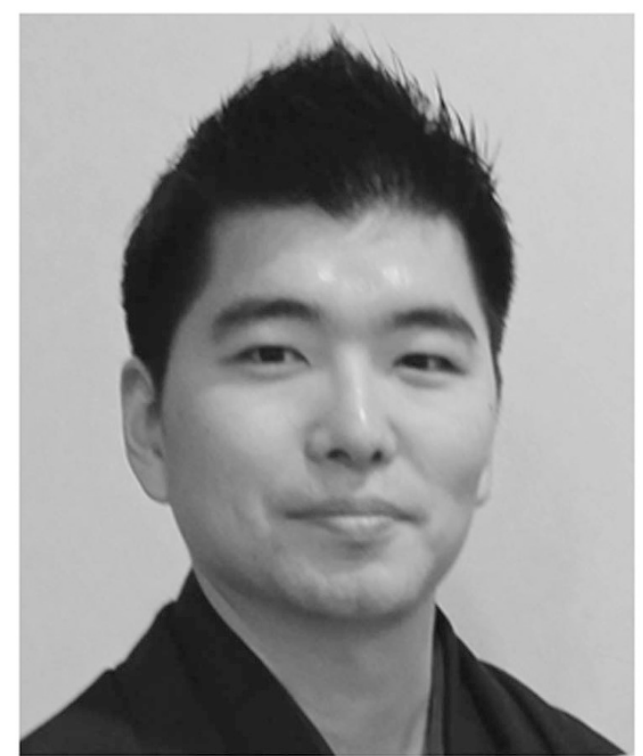

Keiji Numata

Dr Numata earned his PhD (2007) from Tokyo Institute of Technology with a thesis centered on biopolymers, especially poly (hydroxyalkanoate), under the supervisions of Professor Yoshiharu
Doi and Asscociate Professor Hideki Abe. He worked as a JSPS Postdoctoral Fellow for Research Abroad in the laboratory of Stern Family Professor in Engineering David L Kaplan, Tufts University, and then moved to RIKEN in 2010 to start up Enzyme Research Team and also to investigate enzymes to synthesize biopolymers including polypeptides.

About the award article: The authors showed the biosynthesis of poly(hydroxyalkanoate), one of the eco-friendly bioplastics, by various deep-sea bacteria (4 types of Colwellia spp., 11 types of Moritella spp. and 18 types of Shewanella spp.) from glucose, fructose, gluconate or from one of the several plant oils as the sole source of carbon at atmospheric pressure. These results provided mechanism of oligo-hydroxyalkanoate synthesis via chain-transfer reaction and can open the door to precisely control molecular weights as well as their distribution in bacterial polymer syntheses.

1 Kojima, C., Fukada, H. \& Inui, T. Synthesis and binding properties of peptidomimetics based on a dendritic polymer. Polym. J. 45, 339-345 (2013).

2 Numata, K., Morisaki, K., Tomizawa, S., Ohtani, M., Demura, T., Miyazaki, M., Nogi, Y., Deguchi, S. \& Doi, Y. Synthesis of poly- and oligo(hydroxyalkanoate)s by deep-sea bacteria, Colwellia spp., Moritella spp., and Shewanella spp. Polym. J. 45, 1094-1100 (2013)

3 Kato, T. PJ ZEON Award for outstanding papers in Polymer Journal 2012. Polym. J. 45, 577-578 (2013). 